Marketing in Asia Group

Asian Journal of Business Research

Volume 10 Issue 2, 2020

ISSN 2463-4522 e-ISSN 1778-8933 DOI: $10.14707 / a j b r .200084$

\title{
How High can you Fly? LCC Passenger Dissatisfaction
}

\author{
Halimin Herjanto \\ $H-E-B$ School of Business and Administration, University of the Incarnate Word, USA
}

\section{Madysen Byrnes}

School of Management, Marist College, USA

Pablo Rivas

School of Engineering and Computer Science, Baylor College, USA

\section{Jati Kasuma}

Faculty of Business and Management, Universiti Teknologi MARA, Sarawak, Malaysia

\begin{abstract}
The Low-cost carriers (LCCs) have become the most preferred and the most important air transportation mode in Asia. However, investigation of this phenomenon in the Asian context is very limited. A better understanding of the LCC phenomenon, specifically LCC passenger dissatisfaction, could help LCC business practitioners improve their service quality and more importantly, maintain their future business profitability and sustainability. In total, 238 LCC passenger reviews on the wellknown travel website TripAdvisor were content analysed and validated by QDA Miner software from Provalis, with results showing that LCC passenger dissatisfaction was mainly generated by flight delay, ground staff attitude, luggage, seat comfort and followed by check-in counter, airline ground announcements, food others, airline responses, additional/personal costs and cleanliness. This study, therefore, aims to examine and discuss the important factors of LCC passenger dissatisfaction. Limitations of this study, future research directions and implications for Asian LCC business practitioners are also presented.
\end{abstract}

Keywords: Low-Cost Carrier, Passenger Dissatisfaction, Asia, QDA Miner, Qualitative, Thematic Analysis. 


\section{Introduction}

As a result of globalization, the global airlines carrying 3.5 billion passengers in 2015 and this trend is expected to double by 2030 (ICAO, n.d.). Rosen (2017) suggests that such promising trend brings more opportunities and drives airlines to open new routes (Ryerson \& Kim, 2018). To attract more passengers, airline industries have also introduced LCC as their new business model. As low budget airlines, LCCs differentiate themselves by offering significantly cheaper airfares with limited services. Because of this pricing strategy, LCCs successfully carried over 1.5 billion passengers in 2018; that is, $25 \%$ of global air travellers selected LCCs as their primary form of air transportation (CAPA, 2019b).

According to Alistair Hartley, Jetstar's group executive manager, the LCC market share will continue to improve with the biggest opportunities in Asia (Cha, 2013). The Asia's significant economic growth has encouraged Asian businesspeople and holidaymakers to travel more. As a result, the seat capacity in the Southeast Asia region has grown from 200 million to 530 million seats (CAPA, 2019a) and half of these travellers prefer to fly via LCCs (Aquino, 2019). To maintain their competitiveness, LCCs maintain their low-cost operations through online pricing, online booking, secondary airport operations, individual seating arrangements, no meal services, intensive aircraft usage and dense seating arrangements (Prasannan \& Das, 2019). However, Jeddi, Renani, Khademi, Shokri and Noordin (2014) suggest that low operation costs serve as a double-edged sword as these generate passenger dissatisfaction. For example, LCC passengers suffer minimum flight comfort (Moon, 2017), lack passenger support (Chiou \& Chen, 2010) and confront inaccurate reservation systems (Vuthisopon \& Srinuan, 2017).

Despite the importance of understanding LCC passenger dissatisfaction, research on this issue in the Asian context is limited. Among those studies that have examined this issue, Nopakhun and Assenov's (2006) Thai investigation found that complicated booking and payment, ticket restrictions and airline reputation were three of the most dominant factors responsible for passenger unhappiness when traveling with LCC. Similarly, Yeoh and Chan's (2011) Malaysian study found that the degree of service performance, service delivery and price influence passengers' degree of dissatisfaction. Furthermore, Sudradjat, Kumara and Susandi's (2014) revealed that ticketing, luggage and flights are regarded as the most problematic issues by Indonesian consumer watchdogs.

There is no doubt that the studies above provide direction and a better understanding of the LCC passenger dissatisfaction phenomena. However, data from these studies above were reliant on predesigned survey questions or semi-structured interview questions. To some extent, survey (Gaur, Herjanto \& Bathula, 2012) and semistructured based qualitative studies (Bryman, 2012) may lead responses and therefore, it may not accurately show the full picture (Hannan, 2007) of LCC passenger dissatisfaction. Further, most of the studies above do not show their measurements or 
interview questions, and therefore the applicability of their findings to today's situation may not be suitable. Additionally, none of these studies investigated passenger dissatisfaction from the online review data perspective. Scholars suggest that online review data offers unbounded assessment of a topic question (Tucker \& Kim, 2011) from more diverse respondents and a larger pool (Zhao, Ye, Pearce \& $\mathrm{Wu}, 2014) .90 \%$ of customers tend to read online reviews before deciding on purchases (Saleh, 2019), and therefore, Lau, Lee and Ho (2005) conclude that massive online review data helps in recognizing the patterns and trends of specific topics and more importantly, it helps to potentially reveal new findings. Despite their importance, Sezgen, Mason and Mayer (2019) suggest that only a few studies have utilized online review data in the investigation of the passenger dissatisfaction phenomenon. Thus, Sezgen et al. (2019) recommend that the investigation of online review data should be extended, because it will provide alternative analysis that enhances our understanding of LCC passenger dissatisfaction. This study, therefore, attempts to extend the investigation on the LCC passenger dissatisfaction phenomenon in the Asian context by utilizing data from an online review site.

\section{Literature Review}

\section{LCC Passenger Dissatisfaction}

Dissatisfaction is a painful, negative emotion, and it is a product of customers' subjective and objective assessment of an overall negative service encounter (Velazquez, Blasco, Contri, \& Saura, 2009). During the evaluation process, customers utilize their cognitive and affective judgments (Velazquez et al., 2009) to examine the degree of perceived discrepancy between their ideal expectations and actual results (Liu, Sun, Li \& Zhou, 2020). The more discrepancy customers experience, the higher their dissatisfaction will be. Understanding customer dissatisfaction is important because it serves as an indicator to measure business performance and customers' willingness to readopt a product or service in the future (Kim, Kim \& Heo, 2019).

Scholars have argued that customer dissatisfaction decreases customer self-esteem (Yagil \& Medler-Liraz, 2019), leads to a deterioration in customer attitude (Kim et al., 2019) and promotes anger (Fornell, Morgeson, Hult \& VanAmburg, 2020), discourages future behavioural intention (Kim et al., 2019), promotes negative wordof-mouth (Herjanto \& Gaur, 2014), encourages complaints (Tatikonda, 2013), increases switching behaviour (Kim \& Chen, 2010) and decreases sales and revenue (Murthy, Rausand \& Virtanen, 2009).

In the context of air-transport, customer or passenger dissatisfaction refers to an unpleasant mental state that occurs when passengers' beliefs, expectations and perceptions toward airline service quality are not confirmed (Dastpak \& Taghinezhad, 2015). As global transportation becomes more convenient, affordable and available, passengers are becoming increasingly impatient and demanding, and therefore more likely to become dissatisfied (de Waal, 2008). According to Byun, Lee and Rye 
(2014), both full-service carriers (FSC) and LCCs offer three service characteristics: physical service, human service and system service. However, Kim and Lee (2011) argue that the level of such services is not identical. Therefore, passenger perceptions and expectations toward FSC and LCC service quality are different (Chavan, 2109) and the levels and sources passenger dissatisfaction are varied (Lim \& Lee, 2019). In general, airline passengers normally evaluate airline service quality based on the airline's service tangibility, reliability, responsiveness, assurance and empathy (Kim $\&$ Lee, 2011). The combination of these factors determines the degree of passenger dissatisfaction.

Lee and Ng's (2019) study revealed that FSC passengers tend to have a higher expectation of service and quality. For example, FSC passengers expect more baggage allowance, greater and easier network connections, safety and add-on ground services such as airport lounges and priority boarding (Zhang, Lin \& Newman, 2015), flight comfort (Woransuwannarak, 2019), flight time punctuality (Rapajic, 2009), personalized service (Koklic, Kukar-Kinney \& Vegelj, 2017) and better loyalty programs (Chavan, 2019). Failure to fulfil such expectations will generate less passenger confidence (Chavan, 2019) and dissatisfaction (Woransuwannarak, 2019). In contrast, Graham (2013) notes that LCC passengers view LCCs as a more affordable option, and therefore Kusumaningrum, Fadillah, Warsito and Octora (2018) suggest that cheaper fares help LCCs to increase their popularity and consumer attachment. According to IATA's (2006) global airline cost performance report, to maintain their low-cost operation and profitability, LCCs generally serve point-topoint, short haul destinations with one or two types of aircraft, utilizing regional or secondary airports and high aircraft utilization rates, and applying a lean management structure. Additionally, LCCs take advantage of online booking and simplify their inflight experience by offering one service class and very limited inflight services.

As noted by Jeddi et al. (2014), the benefits of LCCs also jeopardize their service quality. LCC passengers may experience dissatisfaction with an airline's service, and ultimately, may encourage passenger-switching behaviour and endanger LCC profitability and sustainability. Sudradjat et al. (2014) have pointed out that the general causes of LCC passenger dissatisfaction are multifaceted, complex and subjective. To name a few, Pan and Truong's (2018) Chinese study revealed that LCC passengers are concerned with their access to the airport. As Jeddi et al. (2014) suggest, one LCC strategy to keep their price low is utilizing secondary or regional airports. According to Grimme (2011), such airports tend to have limited passenger transfer and connection facilities, and therefore this may disrupt passengers' time schedules. Similarly, Etani's (2019) study on Peach airline, a Japanese LCC, found that flight delays generate passenger dissatisfaction. Bubalo and Gaggero (2015) found that one of the most frequent causes of flight delay is that LCCs do not have enough aircraft presence at the airports.

In addition to the issues discussed above, LCCs also experience specific operational issues. For example, Thanasupsin, Chaichana and Pliankarom's (2010) study in Thailand found that LCC passengers' main dissatisfaction concerns price. Their study 
revealed that although lower price is the main attraction for LCC passengers, additional costs are their main concern. Passengers explained that the LCC pricing strategy is biased; that is, when the airlines start adding additional services such as meals and inflight facilities, the LCC price is no less competitive. In a similar study, Nopakhun and Assenov (2006) investigated LCC passenger problems in Thai, and found that in addition to price, LCC passengers are concerned with ticket restrictions, punctuality and poor luggage handling. Passenger argue that LCC tickets are not refundable and excessively restrictive. It is challenging to rectify small errors such as changing a customer's name or adjusting a flight schedule. Yeoh and Chan (2011) replicated this study in Malaysia and found that LCC passengers are mainly dissatisfied with service performance, service delivery and price. In other words, poor service performance and service delivery attributes, such as cleanliness and flight comfort, and LCCs' inability to control passengers' negative behaviour are responsible for generating passenger dissatisfaction. Furthermore, Sudradjat et al.'s (2014) study on LCC service recovery found that LCCs' tangible service components such as ticketing, luggage and flights are regarded as the most problematic issues by Indonesian consumer watchdogs. These studies above show that the findings are mixed and inconclusive and therefore, further study on service failure is important as new findings can provide different consequences (Van de Walle, 2016).

\section{Method}

This exploratory study follows Herjanto, Erickson and Calleja's (2017) thematic analysis to identify the themes involved in LCC passenger dissatisfaction. According to these authors, thematic analysis allows researchers to discover patterns within the qualitative data and is therefore considered as a helpful and suitable method for a meta-analysis study. In order to maintain the robustness of this study, the authors followed Braun and Clarke's (2006) two critical processes of thematic analysis. The first process is the identification of themes, while the second process is a confirmation of themes. Both the deductive and inductive approach are used in this study to identify the antecedents of LCC passenger dissatisfaction. To identify initial, tentative themes, this study utilized a deductive approach and adopted Sezgen et al.'s (2019) five themes. These are as follows: (1) Flight discomfort, which explains issues related to seat comfort and legroom. (2) Flight disruption, which focuses on passengers' long waiting time at the airport due to missed connecting flights, cancellations or delays. (3) Poor service delivery, which relates to staff behaviour. (4) Poor customer care, which describes airlines' inability to provide updated information and recovery services. (5) Extra charges, which are additional charges for additional services. According to the FoodRisc Resource Center (2016) led by Professor Patrick Wall of University College Dublin, Ireland, an initial deductive thematic approach is helpful in identifying tentative themes and is suitable when researchers are looking for similarities and differences amongst these tentative themes.

Next, to observe the current antecedents of LCC passenger dissatisfaction, the authors collected customer reviews posted on two of the biggest Asian LCCs using TripAdvisor 2018. The TripAdvisor site was selected for the following reasons: Firstly, it has a wide network and presents more than 730 million user opinions (Lock, 
2019). Secondly, $86 \%$ of TripAdvisor users believe that the site is trustworthy and gives them more confidence in their decisions (TripAdvisor, 2019). To eliminate misunderstanding and misinterpretation, only comments or reviews written in English with either 1/2 (poor) and 1/1 (terrible) between January 2018 and December 2018 were included. Any comments that were written in foreign languages and were irrelevant to the subject of LCC dissatisfaction were excluded. In total, 238 dissatisfaction related comments were included. Next, following Kristen, Patsy and Fiona (2012), these comments were analysed using an inductive coding approach, whereby each response was carefully analysed, coded and placed into one of several themes. The inductive approach allows researchers to condense textual or narrative data into a summary format (Gabriel, 2013). It also helps in establishing a clear relationship between the research question and the summary finding from the narrative data and more importantly, in developing a model theory from the textual data (Thomas, 2006). Each response was read, re-read and manually coded and classified using an Excel file (Vazin et al., 2016). Through review of these codes based on the original LCC passenger comments, the authors grouped these codes into the respondent's origin, airline route, airline attributes (legroom, seat comfort, inflight entertainment, customer service, value for money and cleanliness) and other comments. During the coding process and search for final themes analysis, some of the coded data fit perfectly to the main themes, whereas other data did not belong anywhere. Therefore, existing themes were dropped or combined, and additional and emerging themes were included. The deductive and inductive approach, therefore, are complementary (Blackstone, 2012) and help researchers to answer their research questions from a broader perspective (Soifeman, 2010).

To ensure understanding of the original meaning of the passenger reviews and that they were correctly coded, as well as to confirm the validity of new themes, this study employed QDA Miner software from Provalis. QDA Miner permits researchers to extract respondent reviews by categories or themes (Angelle \& Schmid, 2007), and cluster them together (Arora \& Stoner, 2009). Therefore, QDA Miner is suitable for research that aims to find relevant and dominant themes (Castonguay, Lavoie, Karazivan, Morris \& Gagnon, 2017). Moreover, QDA Miner also allows researchers to examine the co-occurrence of codes within a paragraph or the entire data. These code co-occurrences can be used to explore similarity and association among cases and variables (Arora \& Stoner, 2009).

Further, as recommended by Holsti (1969), the authors conducted inter-coder reliability and judgments. The authors found the reliability coefficient in this study met the minimum threshold value of $85 \%$ and therefore the intercoder reliability was found to be satisfactory. The reliability of flight delay, luggage-handling errors and seat comfort was $95 \%$, while the reliability of ground staff attitude, cleanliness and check-in counter was 93\%. Further, the reliability of food, airline ground announcements, airline responses and additional/personal costs was 92\%, 99\%, 96\% and $90 \%$ respectively. Differences between the authors were discussed and resolved through professional discussion. 


\section{Findings and Discussion}

238 LCC passenger reviews were coded by QDA Miner software. The results demonstrate that 10 different themes were responsible for LCC passenger dissatisfaction. These themes are flight delay, ground staff attitude, luggage-handling errors, seat comfort, check-in counter, food, airline ground announcements, airline responses, cleanliness and additional/personal costs. The final themes of LCC passenger dissatisfaction are presented in Figure 1. Among these themes, QDA Miner analysis showed that flight delay, ground staff attitude, luggage-handling errors and seat comfort were responsible for $26.1 \%, 24.3 \%, 16.1 \%$ and $11.3 \%$ of passenger dissatisfaction respectively. The remaining themes were responsible for less than $10 \%$ of passenger dissatisfaction. Thus, the first four themes are considered as primary themes of LCC passenger dissatisfaction.

Table 1: Frequency of Theme Occurrences

\begin{tabular}{|l|c|c|c|}
\hline \multicolumn{1}{|c|}{ Themes } & Category & Cases & $\begin{array}{c}\text { Strength of Relationship } \\
\text { Value }\end{array}$ \\
\hline Flight Delay & Ground & 60 & 0.261 \\
\hline Ground Staff Attitude & Ground & 56 & 0.243 \\
\hline Luggage & Ground & 37 & 0.161 \\
\hline Seat Comfort & Air & 26 & 0.113 \\
\hline Check-In Counter & Ground & 21 & 0.091 \\
\hline Airline Ground Announcements & Ground & 19 & 0.083 \\
\hline Food Others & Air & 19 & 0.083 \\
\hline Airline Responses & Ground & 14 & 0.061 \\
\hline Additional/Personal Costs & Ground & 14 & 0.061 \\
\hline Cleanliness & Air & 13 & 0.057 \\
\hline
\end{tabular}

\section{The Primary Themes of LCC Dissatisfaction}

QDA Miner analysis showed that flight delay had a 0.261 connecting or strength of relationships value and was thus considered the most important theme responsible for LCC passenger dissatisfaction. For LCC passengers, flight delays generated discomfort and were considered as a time wasting and inconvenient. In addition, passengers felt that LCCs did little to rectify this issue and expected their customers to accept the situation. The comments below illustrate these arguments:

"I experience delay for at least 2 hours. Imagine how much time I have wasted." (R30)

"I felt uncomfortable because I have to switch or reschedule my plans..." (R213)

"They delay the flight.... Because they think their ticket is cheap. This giving the feeling like they do not care with passengers." (R16)

Ground staff attitude had a strength of relationships value of 0.243 and is regarded as the second theme that generates passenger dissatisfaction. During their interactions with airline ground staff, LCC passengers paid attention to ground staff attitude. Factors like unfair treatment, no ownership and being unapologetic, arrogant and uncaring are regarded as negative attitudes that trigger LCC passenger dissatisfaction. The following comments illustrate this: 
"My observation shows that some ground staff were overzealous with foreign travelers but very lenient with local ones." (R8)

"This is a huge mistake, but they did not offer a proper apologize to all passenger." (R12)

"They are arrogant and treated their customers like dirt!" (R20)

The result of these findings supports Sezgen et al.'s (2019) study on economy class passenger dissatisfaction. In their research, they found that flight disruption (flight delay) and staff attitude were two of the most frequent causes of passenger complaints. According to these authors, a punctual flight schedule and a positive staff attitude are basic necessities and non-negotiable attributes that LCCs must maintain. For passengers, flight delay can mean disaster because they are missing connecting flights, wasting time, rescheduling their agendas (Sezgen et al., 2019) and incurring financial losses (Keselova \& Hanak, 2019). More importantly, flight delay creates emotional distress (Jiang, Li, Huang \& Scott, 2019) and erodes passenger trust in the airline (Chakrabarty, 2019). In sum, Jiang et al. (2019) suggest that flight delay is a source of massive inconvenience to passengers. In addition, ground staff represent passengers' first encounter with their flight experience. Experiencing unpleasant interactions and bad treatment from ground staff will affect passengers' entire flight experience. Therefore, maintaining flight punctuality and a positive staff attitude will not only fulfil the basic needs of passengers but more importantly, they will strengthen the business survival and sustainability of LCCs (Mostert, Meyer \& Rensburg, 2009).

The third theme considered as a major factor in generating LCC passenger dissatisfaction is luggage-handling errors. This theme had a strength of relationships value of 0.161 . The study found that inaccuracy in baggage handling, lost baggage and baggage security are three main factors to trigger dissatisfaction. The following comments support the above arguments:

"The baggage was arrived in wrong terminal, and all passenger need to wait for 1 hour." (R12)

"I waited until the last moment, but I did not see my luggage." (R10)

"Our bag was slashed open at the side and all expensive items have been stolen." (R33)

Chiou and Chen (2010) argue that LCC passengers view luggage handling as an important indicator of LCC performance. That is, passengers compare how LCCs handle their luggage with other airlines. From passengers' perspective, their luggage consists of important and irreplaceable items as well as travel memories and emotional possessions. Losing or receiving broken items not only represents a financial loss but also the erasure of travel memories. Correia, Wirasinghe and de Barros (2008) point out that dealing with such a situation costs passengers time, energy and effort and thus generates a negative experience and negative emotions. Thus, eliminating luggage handling errors would clearly reduce passenger dissatisfaction. 
The next theme is seat comfort, a factor that had a 0.113 strength of relationships value with LCC passenger dissatisfaction. Wicker, Kiefer and Dilger (2015) argue that as a tangible or physical component, airline seats help passengers to justify their spending decision. The size, design and materials of airline seat help LCC passengers to justify the quality of LCC performance (Palmer, 2003). In other words, the more comfortable the seat is, the more confident LCC passengers are in making their decision. In contrast, the less comfortable the seat is, the higher the feeling of dissatisfaction amongst LCC passengers. The following comments support these arguments:

"The seats were so close to each other that you have to sit up right throughout the journey. My seat was faulty. It keeps moving backwards. The leather on the seats peeled off." (R11)

"The seat is extremely uncomfortable, thinner than the seats of a bus." (R67)

"The seat in the aircraft were usual and one of the hand-rest plastic cover was broken causing a minor cut in my son's leg." (R100)

These findings lend support to Baker's (2013) study on American airline passenger satisfaction. In his investigation, Baker (2013) found that over a period of time, airline passengers have become increasingly agitated and intolerant as airlines have continued to reduce passenger comfort and expand aircraft passenger capacity by replacing passenger seats with those of basic quality and smaller size. Accordingly, passengers have less comfortable seats, narrower legroom (Baker, 2013) and experience discomfort and dissatisfaction.

\section{The Secondary Themes of LCC Dissatisfaction}

Check-in counter had a strength of relationships value of 0.091 and is considered as the most dominant secondary theme. According to Tang (2010), the most important function of the check-in counter is to provide the best service to passengers. For example, providing enough ground staff to attend a functional check-in counter and who are proficient in what they do, fully functional check-in equipment, efficient check-in systems and good signage at check-in counters are essential to providing a good passenger service. The following comments illustrate this:

"Check-in counter is disorganized and unprofessional. All they could say was they needed to prepare the check-in machine." (R29)

\section{"Check-in counter was unattended." (R95)}

"Check-in counter is totally mismanaged and in a mess. Passengers are thronging in the front of check-in counter without any queue." (R59)

These findings concur with those of Charoensettasilp and $\mathrm{Wu}$ (2013), who found that a functioning check-in counter is essential to ensure the effectiveness of airline ground operations and is an important factor in generating passenger peace of mind. As Parlar, Rodrigues and Sharafali (2018) note, in general, airline passengers experience high anxiety when they are waiting to board a flight. To reduce such 
anxiety, Parlar et al. (2018) suggest that the check-in counter should provide a quick, errorless check-in experience and more importantly, reduce the queuing line. This promotes satisfaction amongst passengers.

The next important themes in this section are food, others and airline ground announcements. Both of these themes had a 0.083 strength of relationships value with LCC passenger dissatisfaction. As discussed earlier, LCCs maintain their profitability by charging for food. Zahari, Salleh, Kamaruddin and Kutut (2011) suggest that airline passengers are emotionally connected to the inflight food. Therefore, any issues related to food (i.e., the availability and variety of food, speed of food service, food hygiene and price reasonableness) is responsible for triggering passengers' negative emotions such as dissatisfaction. For example,

"This flight did not have the meal options that I wanted and which were part of the on-board menu provided..." (R43)

"Seriously, 6 EUR for peanuts and water? This is hilarious!" (RI)

"They did not have the variety of food in the menu.... disappointing!" (R40)

These findings are consistent with those of Messner (2016), who pointed out that inflight food makes passengers happy. According to de Syon (2008), inflight food selection, food setting and presentation help reduce passengers' flight anxiety and at the same time, improve their flight comfort. According to Lee and Ko (2016), LCC passengers view the provision of inflight food as the value added of their flight experience and the price they pay. Consequently, the more comfortable passenger is with their food, the more satisfied they will feel.

As discussed earlier, Parlan et al. (2018) suggest that the flight experience can be overwhelming and stressful to some of passengers. These passengers may worry about missing their flights or not knowing their departure gate and therefore, they remain on high alert and pay close attention to any information given by the airport or airlines. Airlines' failure to provide up-to-date information not only increases passenger anxiety but also generates high dissatisfaction. The following comments illustrate the discussion above:

"There were no-announcements made and no changes made on the information screen - this was quite unprofessional." (R4)

"The airline delays the flight without confirmation. They made us waiting more than 90 minutes without tell us when the airplane will depart. This gives the feeling that they don't really care with passenger." (R25)

The above comments support the study of Zidarova and Zografos (2011), who found that airline ground announcements are important in lowering passenger dissatisfaction. According to these authors, clear and sound announcements at the airport provide comfort and convenience and improve passengers' positive perception of services. Airline passengers view the accuracy and availability of airline ground announcements as genuine efforts by airlines to ensure passengers do not miss their 
flights (Chen, Batchuluun \& Batnasan, 2005). Accordingly, this effort improves passenger satisfaction (Zidarova \& Zografos, 2011).

Airline responses and additional/personal cost are the next two important sources of passenger dissatisfaction. These two themes had a 0.061 strength of relationships value with LCC passenger dissatisfaction. Jiang and Zhang (2016) suggest that passengers view airlines' willingness to respond to passenger concerns and complaints as a reflection of service quality, which lowers passenger dissatisfaction. These authors highlight that passengers specifically appreciate the promptness and accuracy of airline responses. For example,

"I send numerous e-mails to the $X$ airline on their website with no response. It is my worst experience." (R26)

"Writing to customer service via email resulted in a nonsensical response with no relevance to the question! Contacting customer service was useless." (R47)

"They simply stopped replying to my email. AVOID this airline." (R14)

These comments lend a support to the study of McCollough, Berry and Yadav (2000) on service recovery. The authors found that that airlines can recover their reputation through their ability to handle passenger complaints - positive responses improve passengers' perception of justice. In other words, passengers should feel that an airline is making an effort in the recovery process and that the airline is treating their complaints fairly. When this need is met, passengers feel lower dissatisfaction.

In this study, additional costs, also known as personal costs, refer to the extra money that passengers are required to spend in order to board an airplane. The findings show that both airline and passenger errors are responsible for incurring additional costs. Below are some comments that represent this theme:

"At the boarding gate, the screen did not show the flight number or destination. If you missed the flight, the airline say that it is not their fault and you will end up paying another ticket. It happened with me last year. I feel it is a scam." (R102)

"We walked in when the flight status was still showing as boarding, there were no last/final call. We were not let to board because they said we were 3 minutes late. We had to get fresh new tickets from other airlines." (R104)

These findings confirm Allerd and Addams' (2000) study on the impact of service quality on customer satisfaction. This study revealed that additional costs not only impose an extra financial burden on customers but more importantly, passenger view this extra cost as reflecting an unclear price structure and the untrustworthiness of the airline (Ternes, Towers \& Scheiwe, 2015). Thus, passengers lack confidence in the airline's service and are suspicious and dissatisfied (Chow, 2008).

The final theme of passenger dissatisfaction is cleanliness, which had a 0.057 strength of relationships value. In this study, cleanliness relates to the aircraft facilities, such as seats, restrooms, insects and the overhead locker. As McKechnie, Grant and Golawala (2011) point out, the aircraft is passenger first tangible experience of the airline. The 
aircraft should be designed to facilitate passenger comfort and to enhance flight experience. Failure to maintain cleanliness directly affects passenger satisfaction. The following comments illustrate this point:

"There was trash and empty water bottles on my seat pocket, crumbs on my seat. It is very disgusting." (R3)

“A lot of mosquitoes, I believe cleaning should be done properly." (R53)

"The cleanliness of the flight and especially the lavatory makes you wonder if it has been cleaned since its purchase." (R113)

As can be seen in the comments above, aircraft cleanliness is a "must" factor in the LCC industry. These findings support Oyewole, Sankaran and Choudhury's (2007) study on Malaysian airline satisfaction. In their study, the authors found that passengers prefer a view a dirty aircraft as reflecting a lack of aircraft maintenance, which further generates a feeling of the airline's untrustworthiness and passenger dissatisfaction.

Figure 1: The Final Themes of LCC Passenger Dissatisfaction

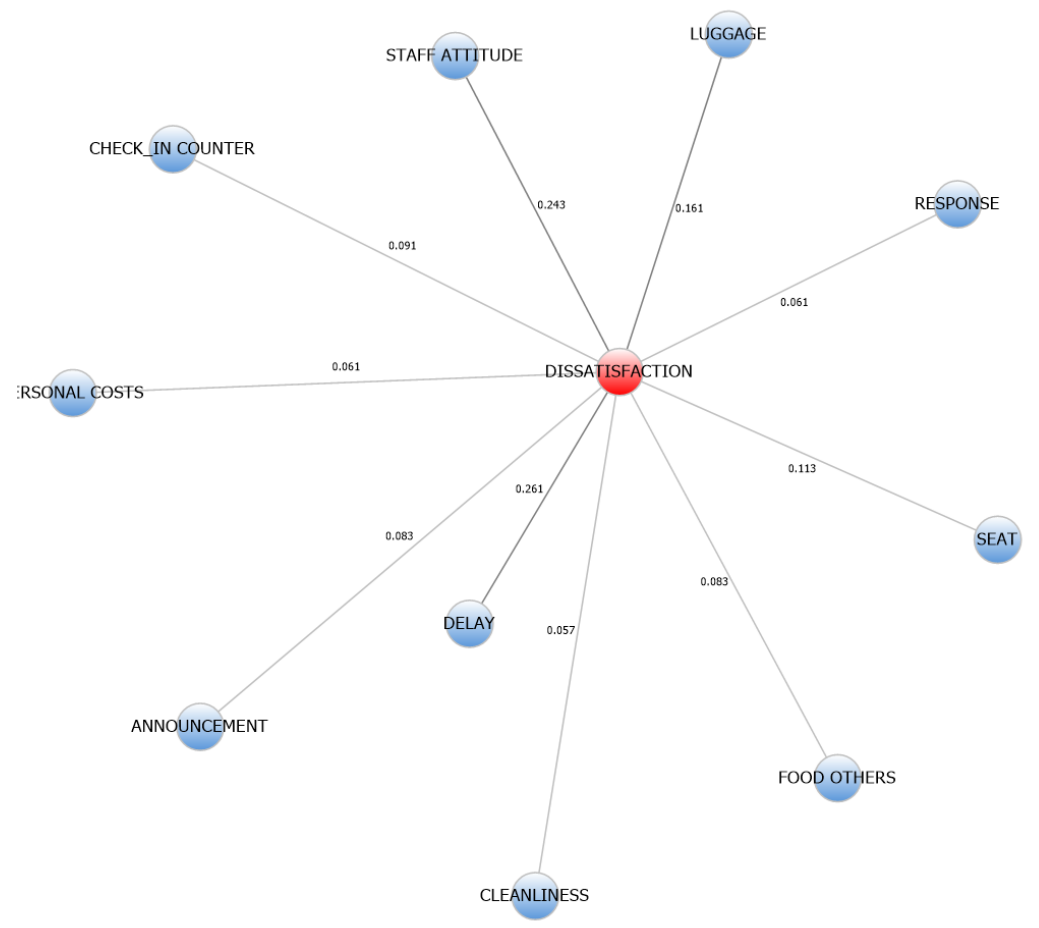




\section{Conclusion, Limitations and Future Research}

The present study provides a better understanding of the LCC passenger dissatisfaction phenomenon, as we now have an idea which themes are important and require urgent attention. The findings show that over 10 years, the LCC passenger dissatisfaction criteria evolved, meaning that LCCs should be strongly aware of areas of concern in order to maintain passenger satisfaction. Based on QDA Miner analysis, four themes - flight delay, ground staff attitude, luggage handling and seat comfort were identified as playing a crucial role in passenger dissatisfaction. Interestingly, LCC passengers were not found to have a problem with cabin crew attitude. Two possible reasons for the major themes of ground staff dissatisfaction may simply be that LCC ground staff lack training (Nguyen, 2019) and that passengers expect ground staff to have the authority to make decisions and to be aware of passengers' needs (Hua \& Li, 2012). Overall, when ground staff are not able to deal with passengers' demands, passengers feel dissatisfied. In addition, the study found that the check-in counter, food, airline ground announcements, airline responses, cleanliness and additional/personal costs are secondary themes in passenger dissatisfaction. This study, therefore, clearly shows that LCCs should prioritize their efforts to minimize passenger dissatisfaction by firstly dealing with the primary themes of passenger dissatisfaction.

Like any studies, the present study has several limitations. The respondents of this study were collected only from Tripadvisor.com. Although 238 reviews were analysed and coded, these reviews related to only two LCC airlines. Therefore, the respondents may only have represented a fraction of the general LCC passenger experience. Thus, the inclusion of more respondents reflecting on different LCC airlines is recommended as this could provide a different picture. In addition, the inclusion of passenger feedback from different travel sites such as airlineratings.com and flight-report.com could offer a different perspective or view of LCC passenger dissatisfaction.

This study lays the foundation for future study. First, in the future, researchers could continue the study by including different LCC airlines from different regions. A wider range of LCC airlines may provide a general picture of LCC passenger dissatisfaction. Second, the researchers could compare passenger dissatisfaction between one region and another. Third, comparing the level of passenger dissatisfaction based on different cabin classes could also provide a general picture of airline passenger dissatisfaction.

\section{Implications for Asian Business Context}

This present study provides business practitioners, especially Asian LCC operations and marketing managers, with a number of important and strategic recommendations based on the four most important themes that Asian LCCs should prioritize to improve their service quality. Firstly, this research found that LCC passengers regard a punctual flight schedule as a basic necessity to make them happy. Respondents showed that in general, LCC passengers can tolerate flight delays when the delay times are short infrequent. That is, passengers are more likely to understand and can accept few minutes delays. Passengers' experience of short delays will not 
significantly affect their schedule and plan. In addition, passengers also regard an occasion delay as acceptable as long as they are well informed about the genuine rationale and cause of delay and are fairly compensated. Therefore, the authors suggest that LCC management should avoid flight delays by ensuring all controllable aspects of flight operations are fully and properly functioning. For example, LCCs should ensure effective and efficient passenger check-in and check-out procedures, maintain aircrafts regularly, redesign their flight schedules (i.e., wider time interval between one flight to the next), and in the most extreme case, have a standby aircraft replacement ready to anticipate unexpected flight schedule disturbance. A wellmaintained aircraft and a well-designed ground operation will not only ensure a punctual flight schedule, but more importantly, it will help avoid passengers' negative flight experience and dissatisfaction. LCCs ability to maintain passenger satisfaction will not only encourage passengers to spread positive WOM and turn them into loyal frequent flyers, but more crucially, will guarantee future business profitability and sustainability.

Secondly, this study strongly suggests that LCCs must have a better luggage handling system. The findings show that LCC passengers want to receive their luggage in a good shape and quickly. Failure to meet this expectation leads to passenger dissatisfied. Because of this, the authors recommend that first, LCCs should offer regular training to their check-in counter staff and luggage handling staff to reduce or eliminate human errors. Second, LCCs are also recommended to implement new luggage handling technology such as radio frequency identification (RFID) technology or global positioning system (GPS) technology. Third, LCCs should also implement a color-coded luggage tag system. That is, LCC could apply a different color luggage tag for a different destination. The combination of fully trained staff, technology and a color-coded luggage system will ensure the effectiveness and efficiency of passenger luggage handling.

Thirdly, respondents' reviews indicate the importance of ground staff attitude. It is extremely relevant that ground staff represent passengers' first encounter with the airline and their subsequent flight experience. The findings note that when ground staff are not prepared to help or to go the extra mile, passengers are likely to have a negative experience and to express dissatisfaction. Thus, to improve passenger satisfaction, it is suggested that LCCs offer a different type of customer service training to their ground staff that prioritizes the passenger experience and more importantly, considers the welfare of ground staff. This would allow ground staff to feel appreciated and happy, and consequently improve their willingness to help passengers.

Finally, LCCs should aware that providing comfortable seating generates positive emotions and a better flight experience. Our respondents' reviews showed that uncomfortable seats, including broken, dirty and small seats, produce ill feeling and disgust. In order to decrease these unpleasant feelings, we recommend that LCCs regularly maintaining their seats, ensure their cleanliness and more importantly, adopt passenger seats that are well-designed. In addition, LCCs also should have different 
types of travel goods available such as neck pillows, cushions, blankets and back pillows. Providing these items will aid passenger comfort during their flights.

\section{References}

Allerd, A., \& Addams, H. L., (2000), "Service quality at banks and credit unions: What do their customer say?", Journal of Service Theory and Practice, vol. 1, no. 1, pp. 52-60.

Angelle, P. S., \& Schmid, J. B., (2007). "School structure and the identity of teacher leaders: Perspectives of principals and teachers", Journal of School Leadership, vol. 17, pp. 771-779.

Aquino, M., (2019), "Southeast Asia's top budget airlines", Retrieved from https://www.tripsavvy.com/southeast-asias-top-low-cost-airlines-1629922

Arora, R., \& Stoner, C., (2009), "A mixed method approach to understanding brand personality", Journal of Product \& Brand Management, vol. 18, no. 4, pp. 272-283.

Baker, D. A., (2013), "Service quality and customer satisfaction in the airline industry: A comparison between legacy airlines and low-cost airlines", American Journal of Tourism Research, vol. 2, no.1, pp. 67-77.

Blackstone, A., (2012), Principles of sociological inquiry - Qualitative and quantitative method, Retrieved from: https://resources.saylor.org/www.resources/archived/site/ textbooks/Principles\%20\%of\%20Sociological\%20Inquiry.pdf

Braun, V., \& Clarke, V., (2006), "Using thematic analysis in psychology", Qualitative Research in Psychology, vol. 3, no. 2, pp. 77-101.

Bryman, A., (2012), Social research methods, Oxford University Press, New York.

Bubalo, B., \& Gaggero, A. A., (2014). "Low cost carrier competition and airline service quality in Europe", Transport Policy, vol. 43, pp. 23-31.

Byun, H., Lee, B., \& Rye, J., (2014). "A comparative study on evaluating the service quality attributes based on Kano Model: A case of low-cost carrier and full-service carrier", SHS Web of Conferences, vol. 12, pp. 1-8.

CAPA, (2019a), "Southeast Asia Airline 2019 outlook: In this fast growth market low costs are essential", Retrieved from: https://centreforaviation.com/analysis/airline-leader/s outheast-asia-airline-2019-outlook-in-this-fast-growth-market-low-costs-are-essential457920

CAPA, (2019b), "LCCs: Global market share gains led by emerging markets", Retrieved from: https://centreforaviation.com/analysis/reports/lccs-global-market-share-gains-ledby-emerging-markets- 459927

Castonguay, V., Lavoie, P, Karazivan, P., Morris, J., \& Gagnon, R., (2017), "Multisource feedback for emergency medicine residents: Different, relevant and useful information", Journal of the Canadian Association of Emergency Physicians, vol. 19, pp. 88.

Cha, F., (2013), "Don't laugh: Vanilla Air, Peach and other budget airlines mean business", Retrieved from http://edition.cnn.com/travel/article/asia-low-cost-carriers/index.html

Chakrabarty, N., (2019), "A data mining approach to flight arrival delay prediction for American airlines", At 9th Annual Information Technology Electromechanical Engineering and Microelectronics Conference, Jaipur, India.

Charoensettasilp, S., \& Wu, C., (2013), "Thai passengers' satisfaction after receiving services from Thailand's domestic low-cost airline", International Journal of u-and e-Service, Science and Technology, vol. 6, no. 6, pp. 107-120.

Chavan, R. R., (2019), "A study on aviation service for low cost carrier and full-service carriers with special reference to Mumbai airport", International Journal of Advance and Innovative Research, vol. 6, no. 1, pp. 135-138.

Chen, J. K. C., Batchuluun, A., \& Batnasan, J., (2015), "Service innovation impact to customer satisfaction and customer value enhancement in airport", Technology in Society, vol. 43, pp. 219-230. 
Chiou, Y. C., \& Chen, Y. H., (2010), "An investigation of service quality in China low cost carrier market", Journal of Eastern Asia Society for Transportation Studies, vol. 8, pp. 2314-2329.

Chow, Y. C., (2008), "Improving the definition and quantification of quality costs", Total Quality management \& Business Excellence, vol. 19, no. 3, pp. 175-191.

Correia, A. R., Wirasinghe, S. C., \& de Barros, A. G., (2008), "A global index for level of service evaluation at airport passenger terminals", Transportation Research Part E, vol. 44, pp. 607-620.

Dastpak, M., \& Taghinezhad, A., (2015), "Persuasive strategies used in Obama's political speech: A CDA approach based on Fairclough's framework", Journal of Applied Linguistics and Language Research, vol. 2, no. 6, pp. 13-27.

de Waal, A. A., (2008), "The secret of high-performance organizations", Management Online Review, 1-10.

de Syon, G., (2008), "Is it really better to travel than to arrive?" In Rubin, L. C. (Ed.) Food for thought. Essays on eating and culture, McFarland Publishers, pp. 199.

Etani, N., (2019), "Development of a predictive model for on-time arrival flight of airline by discovering correlation between flight and weather data", Journal of Big Data, vol. 6, no. 85 , pp. 1-17.

FoodRisc Resource Centre, (2016), "Thematic analysis", Retrieved from: http://resource centre.foodrisc.org/qualitative-analysis_187.html

Fornell, C., Morgeson, F. V., Hult, T. M., \& VanAmburg, D., (2020), "Customer complaints: Learning to love your angry customers. In C. Fornell, F. V., Morgeson., T. M., Hult., \& VanAmburg, D., (Eds.), The reign of the customer, Palgrave MacMillan, Switzerland.

Gaur, S., Herjanto, H., \& Bathula, H., (2012), "Does buyer seller similarity affect buyer satisfaction with the seller firm?", The International Review of Retail Distribution and Consumer Research, vol. 22, no. 3, pp. 315-335.

Gabriel, D., (2013), "Inductive and deductive approaches to research", Retrieved from: https://deborahgabriel.com/2013/03/17/inductive-and-deductive-approaches-to-research /

Graham, A., (2013), "Understanding the low-cost carrier and airport relationship: A critical analysis of the salient issues", Tourism Management, vol. 36, pp. 66-76.

Grimme, W., (2011), "The growth of Arabian airlines from a German perspective - A study of the impacts of new air services to Asia", Journal of Air Transport Management, vol. 17, pp. 333-338.

Hannan, A., (2007), "Interviews in education research", Retrieved from: http://cecs6200.pbworks.com/w/file/fetch/69409200/UsingInterviewsinEducationResea rch.pdf

Helou, S., Yamamoto, G., Kondoh, E., Tamura, H., Hiragi, S., Sugiyama, O., Okamoto, K., Nambu, M., \& Kuroda, T., (2018), "Understanding the roles of EMR systems in Japanese antenatal care settings", Studies in Health Technology and Informatics, vol. 251, pp. 257-260.

Herjanto, H., Ericson, E., \& Calleja, N. F., (2017), “Antecedents of business travellers' satisfaction", Journal of Hospitality Marketing \& Management, vol. 26, no. 3, pp. 295275.

Herjanto, H., \& Gaur, S., (2014), "Romantic tourists' cognitive dissonance and willingness to revisit Asian hotel", Asian Journal of Business Review, vol. 4, no. 2, pp. 16-27.

Holsti, O. R., (1969), Content analysis for the social science and humanities, Addison Wesley, Reading.

Hua, Y. C., \& Li, C. H., (2012), "Exploring the perceived competence of airport ground staff in dealing with unruly passenger behaviours", Tourism Management, vol. 33, no. 3, pp. 611-621.

IATA, (2006), "Airline cost performance", Retrieved from: https://www.iata.org/wha twedo/Documents/economics/airline_cost_performance.pdf

ICAO, (n.d.), "Low cost carriers (LCCs)", Retrieved from: https://www.icao.int/sustaina bility/Pages/Low-Cost-Carriers.aspx 
Jiang, H., \& Zhang, Y., (2016), "An investigation of service quality, customer satisfaction and loyalty in China's airline market", Journal of Air Transport Management, vol. 57, pp. 80-88.

Jiang, Y., Li, S., Huang, J., \& Scott, N., (2019), "Worry and anger from flight delay: Antecedents and consequences", International Journal of Tourism Research, vol. 22, no. 3, pp. 289-302.

Jeddi, A. R., Renani, N. G., Khademi, A., Shokri, V., \& Noordin, M. Y., (2014), "Low cost strategy factors in airline industry: The AirAsia case", Advanced Materials Research, vol. 845, pp. 652-657.

Kaselova, M., \& Hanak, P., (2019), "Risk and opportunity in the process of flight delay", At New Trends in Aviation Development (NTAD) Conference, Chlumec nad Cidinou, Czech Republic.

Kim, B., Kim, S., \& Heo, Y., (2019). "Consequences of customer dissatisfaction in upscale and budget hotels: Focusing on dissatisfied customers' attitude toward a hotel", International Journal of Hospitality \& Tourism Administration, vol. 20, no. 1, pp. 1546.

Kim, J. H., \& Chen, J. S., (2010), "The effects of situational and personal characteristics on consumer complaint behaviour in restaurant services", Journal of Travel \& Tourism Marketing, vol. 27, pp. 96-112.

Kim, Y. K., \& Lee, H. R., (2011), "Customer satisfaction using low cost carriers", Tourism Management, vol. 32, pp. 235-243.

Koklic, M. K., Kukar-Kinney, M., \& Vegelj, S., (2017), "An investigation of customer satisfaction with low-cost and full-service airline companies", Journal of Business Research, vol. 80, pp. 188-196.

Kristen, R., Patsy, Y., \& Fiona, C., (2012), "End-of-life care in the intensive care setting: A descriptive exploratory study of nurses' beliefs and practices", Australian Critical Care, vol. 25, no. 1, pp. 4-12.

Kusumaningrum, M., Fadillah, A., Warsito, T., \& Octora, Y., (2018), "Service performance, brand image and repurchase intention. A study comparison of Citilink and Lion Air Airlines", Advances in Transportation and Logistics Research, pp. 772-780.

Lau, K. N., Lee, K. N., \& Ho, Y., (2005), "Text mining for the hotel industry", Cornell Hotel and Restaurant Quarterly, vol. 10, no. 1, pp. 344-362.

Lee, C. K. M., \& Ng, K. K. H., (2019), "A multi group analysis of social media engagement and loyalty constructs between full service and low-cost carriers in Hong Kong", Journal of Air Transport Management, vol. 73, pp. 46-57.

Lee, J. E., \& Ko, S. H., (2016), "Effect of the in-flight meal service quality on the customer value and loyalty", Indian Journal of Science and Technology, vol. 9, no. 26, pp. 1-6.

Lim, J., \& Lee, H. C., (2019), "Comparisons of service quality perceptions between full service carriers and low-cost carriers in airline travel", Current Issues in Tourism, pp. $1-16$.

Liu, Q., Sun, J., Li, Q., \& Zhou, Z., (2020), "Body dissatisfaction and smartphone addiction among Chinese adolescents: A moderated mediation model", Children and Youth Services Review, vol. 108, pp. 1-9.

Lock, S., (2019), "TripAdvisor - Statistics \& Facts", Retrieved from: https://www.statis ta.com/topics/3443/tripadvisor/

McCollough, M. A., Berry, L. L., \& Yadav, M. S., (2000), "An empirical investigation of customer satisfaction after service failure and recovery", Journal of Service Research, vol. 3, no. 2, pp. 121-137.

McKechnie, D. S., Grant, J., \& Golawala, F. S., (2011), "Partitioning service encounters into touchpoints to enhance quality", International Journal of Quality and Service Sciences, vol. 3 , no. 2 , pp. 146-165.

Messner, W., (2016), "The impact of an aircraft's service environment on perceptions of inflight food quality", Journal of Air Transport Management, vol. 53, pp. 123-130. 
Moon, J. Y., (2017), "Effects of the service satisfaction of flight information system on customer satisfaction and the rate of return customers in Korea - focus on low cost carrier", Journal of Theoretical and Applied Information Technology, vol. 95, no. 18, pp. 4455-4462.

Mostert, P. G., Meyer, D., \& Rensburg, L. R. J., (2009), "The influence of service failure and service recovery on airline passenger's relationships with domestic airline: An exploratory study", South African Business Review, vol. 13, no. 2, pp. 10-21.

Murthy, D. N. P., Rausand, M., \& Virtanen, S., (2009), "Investment in new product reliability", Reliability Engineering \& System Safety, vol. 94, no. 10, pp. 1593-1600.

Nguyen, T. T. T., (2019), "Poor ground service agent attitude at Vietjet aviation joint stock company", Unpublished Master thesis - University of Economics Ho Chi Minh City.

Nopakhun, S., \& Assenov, I., (2006), "Low cost airlines in Thailand: Differentiation or price competition?", At 5th Asia Pacific Forum: Threats and challenges to the tourism industry - Reform and perform. Sept 20-26, Bangkok, Thailand.

Oyewole, P., Sankaran, M., \& Choudhury, P., (2007), "Marketing airline services in Malaysia: A consumer satisfaction orientation approach", Innovative Marketing, vol. 3, no. 1 , pp. 56-70.

Palmer, A., (2003), The Marketing of services. In M. J. Baker (eds). The Marketing Book, 5the ed. Butterworth-Heinemann: Burlington, MA. USA, pp. 585.

Pan, J. Y., \& Truong, D., (2018), "Passengers' intentions to use low-cost carriers: An extended theory of planned behaviour model", Journal of Air Transport Management, vol. 69 , pp. 38-48.

Parlar, M., Rodrigues, B., \& Sharafali, M., (2018), "Event based allocation of airline check-in counters: A simple dynamic optimization method supported by empirical data", International Transactions in Operational Research, vol. 25, no. 5, pp. 1553-1582.

Prasannan, A., \& Das, D., (2019). "Low cost airlines market overview", Retrieved from: https://www.alliedmarketresearch.com/low-cost-airlines-market

Rapajic, J., (2009), "Beyond airline disruption", Ashgate Publishing Limited, Surrey.

Rosen, E., (2017), "As billions more fly, here's how aviation could evolve", Retrieved from: https://www.nationalgeographic.com/environment/urban-expeditions/transportation/airtravel-fuel-emissions-environment/

Ryeson, M. S., \& Kim, A. M., (2018), "A drive for better air service: How air services imbalances across neighbouring regions integrate air and highways demands", Transportation Research Part A, vol. 114, pp. 237-255.

Saleh, K., (2019), "The importance of online customer reviews". Retrieved from: https://www.invespcro.com/blog/the-importance-of-online-customer-reviewsinfographic/

Sezgen, E., Mason, K. J., \& Mayer, R., (2019), "Voice of airline passenger: A text mining approach to understand customer satisfaction", Journal of Air Transport Management, vol. 77, pp. 65-74.

Soifeman, K. L., (2010), "Compare and contrast inductive and deductive research approaches", Retrieved from: https://files.eric.ed.gov/fulltext/ED542066.pdf

Sudradjat, A. S., Kumara, G. K., \& Susandi, N., (2014). "Complaint handling and service recovery analysis at low carrier airline and effects on customer satisfaction in Indonesia", International Journal of Science and Research, vol. 3, no.1, pp. 181-186.

Tang, C. H., (2010), "A network model for airport common use check-in counter assignments", Journal of the Operational Research Society, vol. 61, pp. 1607-1618.

Tatikonda, L., (2013), "The hidden costs of customer dissatisfaction", Management Accounting Quarterly, vol. 14, no. 3, pp. 34-43.

Thanasupsin, K., Chaichana, S., \& Pliankarom, S., (2010), "Factor influencing mode selections of low-cost carriers and a full-service airline in Thailand", Transportation Journal, vol. 5, no. 1, pp. 36-47.

Ternes, A., Towers, I., \& Scheiwe, T., (2015), "Sustainable customer service as success factor in the airline sector", Arabian Journal of Business and Management Review, vol. 5, no. 2, pp. 1-9. 
Thomas, D. R., (2006), "A general inductive approach for analysing qualitative evaluation data", American Journal of Evaluation, vol. 27, no. 2, pp. 237-246.

TripAdvisor, (2019), "Online reviews remain a trusted source of information when booking trips, reveals new research", Retrieved from: http://ir.tripadvisor.com/news-releases/ne ws-release-details/online-reviews-remain-trusted-source-information-when-booking

Tucker, C., \& Kim, H. M., (2011), "Predicting emerging product design trend by mining publicly available customer review data", At ICED11-International Conference on Engineering Design, August 15-18, 2011, Denmark.

Van de Walle, S., (2016), "When public services fail: A research agenda on public service failure", Journal of Service Management, vol. 27, no. 5, pp. 831-846.

Vazin, R., McGinty, E. E., Dickerson, F., Dalcin, A., Goldsholl, S., Enriques, M. O., Jerome, G. J., Gennusa, J. V., \& Daumit, G. L., (2016), "Perceptions of strategies for successful weight loss in persons with serious mental illness participating in a behavioural weight loss intervention: A qualitative study", Psychiatric Rehabilitation Journal, vol. 39, no. 2, pp. 137-146.

Velazquez, B. M., Blanco, M. F., \& Contri, G. B. \& Saura, I. G., (2009), "Cognitive and affective causes of consumer dissatisfaction with the hospitality encounter", Journal of Hospitality Marketing and Management, vol. 18, no 7, pp. 637-675.

Vuthisopon, S., \& Srinuan, C., (2017), "Low cost carrier passenger repurchase intention: A structural equation model analysis", Asia Pacific Social Science Review, vol. 17, no. 2, pp. 249-266.

Wicker, P., Kiefer, S., \& Dilger, A., (2015), "The value of sporting success to Germans: Comparing the 2012 UEFA championships with the 2012 Olympic", Journal of Business Economic, vol. 85, pp. 897-919.

Worasuwannarak, B., (2019), "Aircraft seat pitching: The study of passenger seat", At Actual economy: Local solutions for global challenges, 2019, Prague, Czech Republic.

Yagil, D., \& Medler-Liraz, H., (2019), "The effect of customer social status and dissatisfaction on service performance", Service Business, vol. 13, pp. 153-169.

Yeoh, E., \& Chan, J. K. L., (2011), "Malaysian low-cost airlines: Key influencing factors on customers' repeat purchase intention", World Applied Sciences Journal, vol. 12, pp. 3543.

Zahari, M. S., Salleh, N. K., Kamaruddin, M. S. Y., \& Kutut, M. Z., (2011), "In-flight meals, passengers' level of satisfaction and re-flying intention", World Academy of Science, Engineering and Technology, vol. 5, pp. 12-26.

Zhao, L., Ye, S., Pearce, P. L., \& Wu, M. Y., (2014), "Refreshing hotel satisfaction studies by reconfiguring customer review data", International Journal of Hospitality Management, vol. 38, pp. 1-10.

Zhang, C., Lin, Y. H., \& Newman, D. G., (2015), "Investigating the effectiveness of repositioning strategies: The customers' perspective", Journal of Travel \& Tourism Marketing, vol. 3, no. 9, pp. 1235-1250.

Zidarova, E. D., \& Zografos, K. G., (2011), "Measuring quality of service in airport passenger terminals", Transportation Research Record: Journal of the Transportation Research Board, vol. 2214, pp. 69-76. 